Revista Brasileira de Higiene e Sanidade Animal

Brazilian Journal of Hygiene and Animal Sanity

\title{
Brucelose Canina: Revisão de Literatura
}

\section{Canine brucellosis: a review}

\author{
Filipe Silva Rodrigues', Gislane Vasconcelos de Souza², Iury Lima Aragão Magalhães, \\ Raquel Ribeiro Colares ${ }^{4}$, Salette Lobão Torres Santiago ${ }^{5}$ \\ ${ }^{1}$ Graduando em Medicina Veterinária, Universidade Estadual do Ceará, \\ filipe.rodrigues@aluno.uece.br \\ ${ }^{2}$ Graduanda em Medicina Veterinária, Universidade Estadual do Ceará, \\ gislane.vasconcelos@aluno.uece.br \\ ${ }^{3}$ Graduando em Medicina Veterinária, Universidade Estadual do Ceará, \\ iury.magalhaes@aluno.uece.br \\ ${ }^{4}$ Graduanda em Medicina Veterinária, Universidade Estadual do Ceará, \\ raquel.colares@aluno.uece.br \\ ${ }^{5}$ Professor Associado da Faculdade de Veterinária, Universidade Estadual do Ceará, \\ salette.santiago@uece.br
}

Resumo: A brucelose canina é uma doença infectocontagiosa crônica, de distribuição mundial, causada por bactérias do gênero Brucella. O principal agente envolvido na manutenção da doença é a Brucella canis, porém há relatos de infecção por Brucella abortus, Brucella suis e Brucella melitensis. A maioria dos cães torna-se infectada por via oral, através da ingestão de produtos contaminados, como placenta, fetos abortados e descargas vaginais. A bactéria é capaz de penetrar por todas as membranas mucosas, incluindo genital, oronasal e conjuntival, além de solução de continuidade na pele. Infertilidade, epididimite, prostatite, orquite, abortos, endometrite e placentite são importantes manifestações clínicas, embora alguns cães permaneçam assintomáticos, apesar da infecção ativa. Existe risco zoonótico para pessoas, especialmente aquelas que lidam com a reprodução em canis ou são expostas a animais infectados. $\mathrm{O}$ diagnóstico é feito, principalmente, por métodos sorológicos, embora o cultivo da bactéria e a avaliação clínica do paciente sejam de grande valia. Tendo em vista a ampla distribuição da brucelose canina no Brasil e mundialmente, além da sua importância no âmbito da saúde pública, a presente revisão objetivou ampliar o conhecimento acerca desta importante enfermidade, abordando aspectos epidemiológicos, clínicos e diagnósticos, além das estratégias para sua prevenção e controle.

Palavras-chave: Brucella canis. Cães. Risco zoonótico.

Abstract: Canine Brucellosis is a chronic infectious disease of worldwide distribution, caused by bacteria of the genus Brucella. The main agent involved in maintaining the disease is Brucella canis, but there are reports of infection by Brucella abortus, Brucella suis and Brucella melitensis. Most dogs become infected orally by ingestion of contaminated products such as placenta, aborted fetuses and vaginal discharges. The bacterium is able to penetrate all mucous membranes, including genital, oronasal and conjunctival, and skin lesions. Infertility, epididymitis, prostatitis, orchitis, abortions, endometritis and placentitis are important clinical manifestations, although some dogs remain asymptomatic despite the active infection. There is a zoonotic risk for people, especially those that handle breeding dogs in kennels or are exposed to infected animals. The diagnosis is made primarily by serological methods, although the cultivation of bacteria and clinical evaluation of the patient are of great value. Given the wide distribution of canine brucellosis 
in Brazil and worldwide, as well as its importance in the field of public health, this review aimed to increase knowledge about this important disease, addressing epidemiological, clinical and diagnostical aspects, beyond strategies for prevention and control.

Keywords: Brucella canis. Dogs. Zoonotic risk.

Autor para correspondência. E. Mail: * salette.santiago@uece.br

Recebido em 10.8.2016. Aceito em 28.12.2016

http://dx.doi.org/10.5935/1981-2965.20160071

\section{Introdução}

A brucelose canina é uma doença infectocontagiosa crônica, de distribuição mundial, que pode acometer canídeos domésticos e silvestres e, ocasionalmente, o ser humano. O principal agente envolvido na manutenção da doença é a Brucella canis, porém há relatos de infecção por Brucella abortus, Brucella suis e Brucella melitensis (GREENE; CARMICHAEL, 2015).

Infecções por B.canis em humanos podem ser consideradas raras, com 52 casos relatados em todo o mundo (DENTINGER, et al., 2015). Geralmente, resulta do contato com cães infectados ou exposição laboratorial ao agente infeccioso. Embora, a maioria dos casos humanos envolvam a apresentação de sintomas leves da doença, como febre recorrente, cefaleia e fraqueza, a infecção, ocasionalmente, pode resultar em doença severa, incluindo aneurismas infecciosos, associada à endocardite brucélica, aborto e osteomielite (KRUEGER, et al., 2014; DENTINGER, et al., 2015 ). A sorologia em humanos evidenciou também a presença de

infecção por $B$. canis inaparente em trabalhadores de canis de reprodução (KRUEGER, et al., 2014).

Apenas os cães são capazes de transmitir a enfermidade, sendo a secreção vaginal, fetos abortados, sêmen e urina contaminados importantes veículos de disseminação, tanto para cães quanto para o ser humano (WANKE, 2004). Nas cadelas, o principal sinal clínico observado é o aborto no terço final da gestação, e nos machos observase epididimite, prostatite e infertilidade, porém a infecção pode ser assintomática. Discoespondilite, uveíte, artrite, meningite e encefalite são manifestações menos comuns (MEGID, 2002).

Desde o primeiro relato, em 1966, que demonstrou o envolvimento de B. canis no surgimento de abortos em cadelas da raça Beagle na cidade de Nova Iorque (CARMICHAEL, 1966), este agente tem sido extensivamente descrito em cães de diversos países através do isolamento da bactéria ou diagnóstico sorológico. No Brasil, inquéritos soroepidemiológicos realizados em diversas regiões do país descrevem prevalências de anticorpos anti- $B$. canis que variam de 0,84 a $45,34 \%$. 
B. canis apresenta propriedades antigênicas semelhantes à Brucella ovis, razão pela qual esta pode ser usada na preparação de antígenos para testes diagnósticos de brucelose canina (HOLLETT, 2006). A sorologia constitui o método diagnóstico mais utilizado para detectar a doença. No Brasil, o teste de imunodifusão em gel de ágar (IDGA) é usado como teste oficial para a brucelose canina (OLIVEIRA, et al., 2011), embora o teste de aglutinação rápida em placa e o teste de aglutinação em tubo, ambos com ou sem adição de 2-mercaptoetanol, sejam amplamente utilizados para o diagnóstico da doença (KEID, et al., 2007). Recentemente, alguns ensaios imunoenzimáticos indiretos, utilizando protocolos variados para obtenção antigênica, e ensaio imunocromatográfico, a partir de kits comercialmente disponíveis, vêm sendo também utilizados para o sorodiagnóstico da doença, demonstrando alta especificidade e sensibilidade diagnósticas (LUCERO, et al., 2002; BARROUIN-MELO, et al., 2007; KIM, et al., 2007; BARKHA, et al., 2011; OLIVEIRA, et al., 2011).

A hemocultura promove um diagnóstico definitivo para B.canis, porém pode exibir resultados negativos em infecções crônicas, recentes ou após administração de antibacterianos (GREENE; CARMICHAEL, 2015). Ainda referente aos métodos diretos para diagnóstico da brucelose canina, a reação em cadeia da polimerase (PCR) e suas variações, PCR multiplex e PCR real-time demonstram alta sensibilidade e especificidades diagnósticas, podendo ser alternativas como testes confirmatórios da doença (KEID, et al., 2007; KEID, et al., 2009; KANG, et al., 2011; WINCHELL, et al., 2010; KADEN, et al., 2014).

Tendo em vista a ampla distribuição da brucelose canina no Brasil e mundialmente, além da sua importância no âmbito da saúde pública, a presente revisão tem como objetivo abordar aspectos epidemiológicos, clínicos e diagnósticos da brucelose canina, além das estratégias para sua prevenção e controle.

\section{Revisão de literatura}

\subsection{Etiologia e epidemiologia}

A brucelose canina é uma doença infectocontagiosa crônica causada por bactérias do gênero Brucella (MEGID et al., 2007). Neste gênero estão incluídas seis espécies clássicas, diferenciadas com base na predileção por determinados hospedeiros e análise genética. Assim, tem-se Brucella abortus (bovinos), Brucella canis (cães), Brucella melitensis (caprinos e ovinos), Brucella neotomae (roedores), Brucella ovis (ovinos) e Brucella suis e seus biovares (suínos, bovinos, lebres, roedores e ungulados silvestres). Duas novas espécies foram isoladas de mamíferos marinhos, Brucella ceti (cetáceos) e Brucella pinnipedialis (pinípedes), no entanto, estes isolados tendem a infectar somente mamíferos marinhos (GREENE; CARMICHAEL, 2015). Recentemente foram recuperadas duas novas espécies, Brucella microti, de raposas 
vermelhas (Vulpes vulpes) (SCHOLZ et al., 2009), e Brucella inopinata, isolada em um implante de seio humano (SCHOLZ et al., 2010).

Os cães podem se infectar por quatro das seis espécies clássicas de Brucella spp. (HOLLETT, 2006). No entanto, apesar de existir relatos de brucelose em cães causada por B. melitensis (HINIC et al., 2010), B. abortus (BICKNELL et al., 1976; FORBES, 1990; BAEK, et al., 2003; MEGID et al., 2007) e B. suis (PLANG et al., 1931; BARR et al., 1986), tais infecções são raras, apresentanto, geralmente, evolução autolimitante e rápida recuperação (ZOHA; CARMICHAEL, 1982). Assim, a principal espécie de importância epidemiológica na brucelose canina é a $B$. canis (CARMICHAEL, 1966; MOORE et al., 1967; CARMICHAEL; KENNEY, 1968; GODOY et al., 1977; MORAES et al., 2002; FERREIRA et al., 2007; BAE; LEE, 2009).

Não existe predileção por raça, idade ou sexo, sendo machos e fêmeas igualmente acometidos pela doença (GERMANO et al., 1987; MORAES et al., 2002; AZEVEDO et al., 2003). Azevedo et al. (2003), ao analisarem a faixa etária como possível fator de risco associado à soropositividade para B.canis, concluiram que animais impúberes e sexualmente maduros estão igualmente expostos ao risco de infecção, sendo que os animais impúberes que adquirem a infecção e se tornam bacterêmicos, normalmente desenvolvem, nestes casos, linfadenopatia uni ou bilateral, e a manifestação dos sinais clínicos reprodutivos ocorre após a puberdade.

Isolada pela primeira vez por Carmichael (1966) na placenta, tecido fetal e descargas vaginais de fêmeas da raça Beagle que abortaram, B.canis é uma pequena bactéria cocobacilar (1,0 a $1,5 \mu \mathrm{m})$, intracelular facultativa, Gram-negativa, aeróbia e imóvel.

As espécies deste gênero de bactéria são sensíveis aos desinfetantes comuns, à luz e à dessecação.

Em clima frio, podem permanecer viáveis por até dois meses em cadáveres ou tecidos contaminados enterrados, resistindo também ao congelamento e descongelamento (GREENE; CARMICHAEL, 2015).

Morisset et al. (1969) descreveram três características primordiais da B.canis: (1) em isolamento primário, esta espécie bacteriana apresenta morfologia colonial mucoide rugosa, por ser desprovida do antígeno somático $\mathrm{O}$, indicando parede celular limitada, e com pouca endotoxina, quando comparada às culturas lisas de outras espécies de Brucella; (2) os organismos brucélicos tendem a se localizar no tecido linfoide, causando considerável hiperplasia; e (3) as infecções resultantes frequentemente permanecem crônicas, com pouca ou nenhuma evidência de doença.

B.canis tem uma limitada preferência por hospedeiros e, apenas, cães e canídeos selvagens demonstram suscetibilidade a este 
micro-organismo, embora, existam alguns poucos relatos de infecção em coelhos, primatas não humanos e no homem. É possível que gatos se infectem experimentalmente e apresentem bacteremia transitória, porém são relativamente resistentes (GREENE; CARMICHAEL, 2015).

De distribuição mundial, B.canis já foi isolada em diversos países, tais como Estados Unidos (CARMICHAEL, 1966; BROWER et al., 2007), México (FLORES-CASTRO; SEGURA, 1976), Canadá (FORBES et al., 1988), China (SHANG et al., 1989), Japão (YAMAUCHI et al., 1974), Itália (CORRENTE et al., 2010), Reino Unido (DUNNE et al., 2002), Alemanha (NOCKLER et al., 2003), África do Sul (GOUS et al., 2005), Zimbabwe (GOMO, 2013), Chile (ZAMORA et al., 1980), e Argentina (LOPES et al., 2009).

No Brasil, existem poucos relatos de isolamento de B.canis. Godoy et al. (1977) foram os primeiros a isolar e identificar a bactéria no Brasil. Em pesquisa realizada na cidade de Belo Horizonte, Minas Gerais, estes autores observaram hemocultura positiva para B.canis em uma cadela com histórico recente de aborto. A bactéria também já foi isolada do humor aquoso de um cão com lesões oculares (FERNANDES et al., 1977). Larsson e Costa (1980), ao testarem 27 cães pelo teste de aglutinação em tubo (TAT) e hemocultura, encontraram cinco animais positivos pelo TAT $(18,51 \%)$ e três $(11,11 \%)$ pela hemocultura. Vargas et al. (1996) isolaram $B$. canis a partir da placenta, fetos abortados e neonatos de duas fêmeas provenientes de um canil na cidade de Uruguaiana, Rio Grande do Sul. Gomes et al. (1999) identificaram este agente a partir de órgãos genitais de cães que apresentavam orquite e epididimite. Em trabalho realizado por Keid et al. (2004), um total de 171 cães, oriundos de canis no estado de São Paulo, foram avaliados quanto à presença de Brucella spp. em amostras de sangue, e anticorpos anti-B.canis pelo método de IDGA, utilizando como parâmetro sinais clínicos sugestivos de brucelose (aborto, falha na concepção, descarga vaginal, orquite, epididimite, uveíte, etc.). Destes cães, 24 $(14,62 \%)$ tiveram hemocultura positiva para B.canis, $58(33,91 \%)$ foram positivos ao IDGA e $39(22,8 \%)$ cães apresentavam sinais clínicos da doença.

Tem-se notado que os cães domiciliados apresentam menor prevalência da brucelose, em comparação com os abandonados e que vivem em áreas de baixo nível econômico.

Este fato pode refletir a maior densidade de animais e acasalamentos descontrolados. Canis de reprodução também podem manter a infecção, caso medidas profiláticas e de controle não sejam implementadas (GREENE; CARMICHAEL, 2015).

Diversas pesquisas envolvendo o diagnóstico sorológico de $B$. canis vêm sendo realizadas ao longo dos últimos cinquenta 
anos no mundo. $\mathrm{O}$ sorodiagnóstico da brucelose canina pode revelar diferenças na prevalência de animais positivos, de acordo com o tipo e interpretação do teste utilizado (BARKHA et al., 2011). Em Wisconsin, nos Estados Unidos, ao se analisar 510 amostras de soros provenientes de cães que habitavam canis da região, encontrou-se prevalência de $1,96 \%$, utilizando o teste de aglutinação rápida em placa (TARP). $\mathrm{Na}$ Argentina, de 224 cães, $33(14,7 \%)$ foram positivos pelo TARP; destes, 24 (10,7\%) foram confirmados através de ensaio de imunoabsorção enzimática indireta (ELISAi) (LOPEZ et al., 2009). Na Colômbia, a soroprevalência da brucelose canina, em canis situados no departamento de Antioquia, foi investigada por Castrillon-Salazar et al. (2013). Neste estudo, foram incluídas 428 amostras de soro, que, ao serem submetidas ao TARP com 2mercaptoetanol (TARP-ME), revelaram soroprevalência de $15 \%$. Em estudo realizado na Coreia do Sul, foram testados soros de 501 cães que viviam em canis, residências ou eram errantes. Destes, detectou-se anticorpos anti-B.canis em $14,1 \%$ dos cães de canis, utilizando o TARP, não havendo casos soropositivos nos cães domiciliados ou errantes (BAE et al., 2009). Em Ontário, Canadá, 2000 amostras de soro, obtidas tanto de cães domiciliados $(n=1445)$, quanto pertencentes a canis $(n=555)$ foram testadas, tendo como resultado $0,3 \%$ de positividade, ao empregar o IDGA (BOSU; PRESCOTT, 1980). Em inquérito sorológico realizado no
México, Flores-Castro e Segura (1976) consideraram os títulos de anticorpos aglutinantes anti- $B$. canis positivos 1:100 ou maior, e encontraram $28 \%$ de amostras séricas positivas nos cães testados. Recentemente, cães de áreas urbanas e rurais do Zimbabwe foram testados quanto à presença de anticorpos IgG anti-B.canis; das 324 amostras séricas obtidas e submetidas à análise pelo ELISA modificado (ImmunoComb®), 57 $(17,6 \%)$ foram positivas (CHINYOKA et al., 2014).

No Brasil, inquéritos sorológicos foram realizados em diversas regiões do país, alguns dos quais estão demonstrados na Tabela 1. Nela notamos que, tendo como base o sorodiagnóstico da brucelose canina, a prevalência de anticorpos anti-B.canis no Brasil variou de 0,84 a 45,34\%. A maioria dos inquéritos soroepidemiológicos se concentram na região sul e sudeste do país, sendo poucos os relatos de soroprevalência no norte e nordeste do país.

Estudos nacionais vêm detectando baixa ocorrência de anticorpos anti- B.abortus em cães, variando de 0 a 18,4 \%, conforme a prova sorológica utilizada (LOPES et al., 1999; CARVALHO, et al., 2000; ALMEIDA et al., 2004; PAZ et al., 2015). Mesmo assim, é importante ressaltar que cães infectados por B. abortus podem constituir fonte de infecção para outros cães e para animais de produção (GREENE; CARMICHAEL, 2015). Portanto, os exames de diagnóstico e a remoção tanto de caninos quanto de bovinos acometidos pela 
B.abortus devem ser considerados quando se pretende a prevenção e erradicação da brucelose em fazendas (FORBES, 1990; GREENE; CARMICHAEL, 2015).

Tabela 1. Inquéritos sorológicos realizados em diversas regiões do Brasil quanto à presença de anticorpos anti-B. canis em cães, no período de 1979 a 2013

\begin{tabular}{|c|c|c|c|c|c|}
\hline Autor & $\begin{array}{l}\text { Número de } \\
\text { Animais }\end{array}$ & Procedência & Soroprevalência & $\begin{array}{c}\text { Teste } \\
\text { Utilizado }\end{array}$ & Cidade/Região \\
\hline $\begin{array}{c}\text { Sandoval et al., } 1976 \\
\text { Wald; Fernandes, 1976- } \\
1977\end{array}$ & $\begin{array}{l}221 \\
192\end{array}$ & $\begin{array}{c}\text { Errantes } \\
\text { Domiciliados }\end{array}$ & $\begin{array}{c}8(3,61 \%) \\
23(11,9 \%)\end{array}$ & $\begin{array}{l}\text { TAT } \\
\text { TAT }\end{array}$ & $\begin{array}{c}\text { São Paulo, SP } \\
\text { Porto Alegre, RS }\end{array}$ \\
\hline Godoy et al., 1977 & 76 & Domiciliados & $1(1,3 \%)$ & TARP & Belo Horizonte, MG \\
\hline Larsson et al., 1981 & 364 & Canis e errantes & $30(8,2 \%)$ & TARP & São Paulo, SP \\
\hline Germano et al., 1986 & 352 & Domiciliados & $19(5,4 \%)$ & TARP-ME & Campinas, SP \\
\hline Cortes et al., 1988 & 3386 & Errantes & $254(7,5 \%)$ & IDGA & São Paulo, SP \\
\hline Carvalho et al., 2000 & 236 & $\begin{array}{l}\text { Domiciliados, } \\
\text { abrigos, canis e } \\
\text { fazendas }\end{array}$ & $107(45,34 \%)$ & IDGA & Belém, PA \\
\hline Moraes et al., 2002 & 1072 & Domiciliados & $\begin{array}{l}19(1,77 \%) \\
9(0,84 \%)\end{array}$ & $\begin{array}{c}\text { TARP } \\
\text { TARP-ME }\end{array}$ & Serra de Botucatu,SP \\
\hline Azevedo et al., 2003 & 410 & $\begin{array}{c}\text { Domiciliados, } \\
\text { semidomiciliados e } \\
\text { errantes }\end{array}$ & $9(2,2 \%)$ & $\begin{array}{l}\text { IDGA IDGA- } \\
\text { ME } \\
\text { FC }\end{array}$ & $\begin{array}{c}\text { Santana de Parnaíba, } \\
\text { SP }\end{array}$ \\
\hline Marassi et al., 2003 & 497 & Domiciliados & $37(7,4 \%)$ & IDGA & Rio de Janeiro,RJ \\
\hline Almeida et al., 2004 & 635 & Domiciliados & $90(14,2 \%)$ & IDGA & Alfenas,MG \\
\hline Aguiar et al., 2005 & 304 & $\begin{array}{l}\text { Domiciliados e } \\
\text { Fazendas }\end{array}$ & $11(3,6 \%)$ & IDGA & Monte Negro, RO \\
\hline Cavalcanti et al., 2006 & 85 & Domiciliados & $5(5,88 \%)$ & IDGA & $\begin{array}{c}\text { Região } \\
\text { Metropolitana de } \\
\text { Salvador }\end{array}$ \\
\hline $\begin{array}{l}\text { Vasconcelos et al., } \\
2008\end{array}$ & 170 & Domiciliados & $4(2,35 \%)$ & IDGA & Campina Grande, PB \\
\hline Dorneles et al., 2011 & 374 & Domiciliados & $167(44,6 \%)$ & IDGA & Araguaína, TO \\
\hline Fernandes et al., 2011 & 193 & Domiciliados & $6(3,11 \%)$ & IDGA & Patos, PB \\
\hline Fernandes et al., 2013 & 416 & Domiciliados & $120(28,9 \%)$ & IDGA & Natal, RN \\
\hline
\end{tabular}

Teste de aglutinação em tubo. IDGA: Imunodifusão em gel de ágar. IDGA-ME: Imunodifusão em gel de ágar com 2-mercaptoetanol. TARP: Teste de aglutinação rápida em placa. TARP-ME: Teste de aglutinação rápida com 2-mercaptoetanol.

\subsection{Transmissão}

A maioria dos cães torna-se infectada por B.canis por via oral, através da ingestão de produtos contaminados, como placenta, fetos abortados e descargas vaginais. A bactéria é capaz de penetrar por todas as membranas mucosas, incluindo genital, oronasal e conjuntival, além de solução de continuidade na pele. A dose infecciosa oral mínima para cães é de, aproximadamente, $10^{6}$ bactérias, ao passo que a dose conjuntival é de $10^{4}$ a $10^{5}$ 
micro-organismos (FLORES-CASTRO; CARMICHAEL, 1981; MAKLOSKI, 2011; GREENE; CARMICHAEL, 2015).

A eliminação da B.canis pode se prolongar por até seis semanas após um aborto. O leite de cadelas infectadas, por conter baixas concentrações do microorganismo, parece ser menos importante na transmissão da infecção aos filhotes que sobrevivem, sendo a contaminação in utero ou de modo congênito mais frequente. Sêmen e urina podem servir como veículos de disseminação, pois cães infectados abrigam os organismos brucélicos na próstata e epidídimo. A taxa de isolamento de $B$. canis do sêmen é especialmente alta nas primeiras 6 a 8 semanas pós-infecção, ocorrendo eliminação intermitente e em baixo número de bactérias por períodos que variam de 60 semanas até dois anos pós-infecção. A excreção urinária começa entre 4 a 8 semanas após o início da bacteremia, continuando por pelo menos três meses. Fontes artificiais de transmissão são vaginoscopia, transfusão sanguínea, inseminação artificial e seringas contaminadas. Por conter as mais altas concentrações de micro-organismos, as secreções vaginais e o sêmen são os veículos mais prováveis de infecção por contaminação de mucosas (HOLLETT, 2006; GREENE; CARMICHAEL, 2015).

A infecção natural de cães por $B$. abortus é de ocorrência esporádica e resulta do contato estreito de cães, geralmente de zona rural, com bovinos infectados. Os cães infectam-se por ingestão de produtos de origem animal in natura, contato ou ingestão de tecidos animais, restos placentários ou de fetos abortados contaminados (MEGID et al., 2007).

\subsection{Patogenia}

As principais rotas de entrada para o patógeno são as mucosas genitais, oronasais ou conjuntivais. Após a entrada da B. canis no hospedeiro, a bactéria é fagocitada por macrófagos e outras células fagocíticas. Estes micro-organismos são capazes de sobreviver dentro dos macrófagos e escapam da fusão com fagolisossomos, sendo carreados aos órgãos linfáticos (linfonodos e baço) e reprodutivos (esteroide-dependente), onde se multiplicam. Em machos, tais órgãos incluem a próstata, testículo e epidídimo. Nas fêmeas têm-se os fetos, útero gravídico e placenta. A bactéria também é encontrada no conteúdo estomacal do feto, sugerindo a contaminação in utero. A placenta abortada apresenta focos de necrose coagulativa dos vilos coriônicos, arterite necrotizante, e numerosas bactérias nas células epiteliais trofoblásticas (WANKE, 2004; HOLLETT, 2006). B.canis pode alcançar, pela bacteremia, outros tecidos, como discos intervertebrais, ou formar complexos antígeno-anticorpo 
na úvea anterior dos olhos (uveíte), rins (glomerulopatia) e meninges (meningoencefalite) (FERNANDES, et al., 1976-1977; HOLLETT, 2006). Nos machos, a inflamação do epidídimo e dos testículos provoca extravasamento de espermatozoides, induzindo resposta imune celular e humoral. As respostas imunes produzidas contra os espermatozoides contribuem para a epididimite, infertilidade e até parada da espermatogênese (HOLLETT, 2006).

Uma importante característica da brucelose canina é a prolongada bacteremia, podendo ser intermitente (CARMICHAEL, 1976). A bacteremia associada a leucócitos inicia-se dentro de 1 a 4 semanas pós-infecção e persiste por, no mínimo seis meses, depois, intermitentemente, por até 64 meses (GREENE; CARMICHAEL, 2015).

Recuperação espontânea pode ocorrer de um a cinco anos depois da infecção inicial. Nestes casos, os cães tornam-se abacterêmicos e com baixos títulos de anticorpos aglutinantes (1:25 ou 1:50), sugerindo a eliminação da bactéria. Os títulos não aumentam quando o animal é desafiado, e não ocorre reinfecção, devido ao desenvolvimento de eficiente imunidade celular na recuperação espontânea. No entanto, cães com infecção crônica que foram tratados com sucesso utilizando fármacos antibacterianos, mostraram-se totalmente suscetíveis à reinfecção oronasal 12 semanas após a interrupção do tratamento. Cultura negativa associada à diminuição do título de aglutinação no soro também pode estar presente em alguns casos onde B.canis persiste em tecidos corporais. A próstata pode constituir um local de persistência dos micro-organismos no macho (HOLLETT, 2006; GREENE; CARMICHAEL, 2015).

\subsection{Sinais clínicos}

Embora, muitas vezes, a infecção por B. canis seja assintomática, cães infectados pela bactéria têm relevante importância na propagação da doença (KEID et al., 2004; WANKE, 2004; FERREIRA et al., 2007). Quando na ocorrência de sinais clínicos, estes podem ser limitados a linfadenopatia periférica, acompanhada ou não de infertilidade em ambos os sexos e raramente acompanhada de febre (FORBES; PANTEKOEK, 1988; CORRÊA; CORRÊA, 1992; KEID et al., 2004).

Abortamentos, que ocorrem principalmente na fase final da gestação, entre os 45 a 59 dias, representam um dos principais aspectos clínicos da doença; porém, o aborto também pode ocorrer em qualquer outra fase da gestação, sendo normalmente caracterizado por autólise fetal e secreção vaginal serosanguinolenta de cor escura e/ou esverdeada com duração 
de uma a seis semanas. Os ciclos estrais das fêmeas se apresentam normais ou com poucas alterações perceptíveis. Os filhotes que sobrevivem podem apresentar linfadenopatia generalizada e manter a infecção até a maturidade sexual (FORBES; PANTEKOEK, 1988; CORRÊA; CORRÊA, 1992).

Congestão, hemorragia subcutânea em região abdominal e edema subcutâneo também podem ocorrer. Os machos maduros podem apresentar epididimite e orquite, o que provocará aumento testicular, com acúmulo de fluido serossanguinolento, além de atrofia testicular uni ou bilateral, com redução do número de espermatozoides e presença de células inflamatórias no ejaculado (FORBES \& PANTEKOEK, 1988; CORRÊA; CORRÊA, 1992; QUINN et al., 2005). Redução da motilidade, da concentração e do volume espermático é geralmente observada, bem como defeitos espermáticos e diminuição na qualidade seminal, evidentes a partir da $4^{\mathrm{a}}$ semana pós-infecção. Pode ocorrer dermatite na bolsa escrotal por lambedura, favorecendo o surgimento de infecções secundárias, principalmente por Staphylococus aureus, (FORBES; PANTEKOEK, 1988; CARMICHAEL; GREENE, 1998).

Por volta da oitava semana pósinfecção as anormalidades espermáticas tornam-se mais evidentes, tais como destacamento de cabeça, cauda fortemente enrolada, acrossomas deformados, peça intermediária dobrada, redução da motilidade (podendo apresentar apenas $10 \%$ de espermatozoides móveis) e a partir da $12^{\mathrm{a}}$ semana aglutinações espermáticas podem ser notadas, devido a resposta autoimune com produção de anticorpos contra os espermatozoides (GEORGE et al., 1979).

Sinais menos frequentes associados à infecção por $B$. canis são abscessos viscerais, discoespondilites, dermatite piogranulomatosa, osteomielites, meningoencefalite, glomerulonefrite e sinais oculares, tais como coriorretinite, vitrite, uveíte anterior, endoftamilte, panuveíte, panoftamite, ceratoconjuntivite e deslocamento de retina (FORBES; PANTEKOEK, 1988; CORRÊA; CORRÊA, 1992; HIRSH \& ZEE, 2003; KEID et al., 2004; LEDBETTER et al., 2009).

\subsection{Diagnóstico}

Semelhante ao que ocorre em casos de brucelose em outras espécies, as manifestações clínicas da brucelose canina são variáveis e, portanto, o diagnóstico não pode se basear somente nos achados clínicos. No entanto, a suspeita clínica é importante para se realizar a investigação da doença, devendo ser realizada sempre que os animais apresentarem histórico de aborto e deficiências reprodutivas, tais 
como epididimite, atrofia testicular e baixa qualidade seminal (FLORES-CASTRO; CARMICHAEL, 1981).

Embora existam vários métodos de diagnóstico, o definitivo é feito através do isolamento da bactéria, que pode ser realizado a partir do sangue, descargas vaginais, leite, baço, epidídimo, linfonodos, secreção prostática, sêmen, vesícula seminal e, em casos de abortamentos, pode-se utilizar placenta e tecidos dos fetos abortados (FLORESCASTRO; CARMICHAEL, 1981; MEGID et al., 2002). É importante salientar que um resultado de cultivo negativo não pode confirmar a ausência de infecção por B.canis, visto que vários fatores, tais como eliminação intermitente da bactéria, material mal colhido e mal conservado e uso de antibióticos podem diminuir a sensibilidade do exame (FLORESCASTRO; CARMICHAEL, 1981; MINHARRO et al., 2005).

Os testes sorológicos são de grande valia para o diagnóstico da brucelose canina, que, por se tratar de uma enfermidade crônica, apresenta a imunoglobulina $\mathrm{G}$ ( $\mathrm{IgG}$ ) como principal classe de anticorpos circulantes. Animais infectados apresentam altos títulos de anticorpos, que podem persistir por vários meses após a fase bacterêmica, podendo durar por até 36 meses (FLORES-
CASTRO; CARMICHAEL, 1981; MINHARRO et al., 2005).

Os quatro principais testes sorológicos utilizados para diagnóstico da brucelose canina são: IDGA, TAT, TARP e TARP-ME (CARMICHAEL et al., 1984). TAT e TARP, com ou sem adição de 2-mercaptoetanol, são indicados como procedimentos de triagem, sendo IDGA o teste confirmatório para o diagnóstico da enfermidade (MINHARRO et al., 2005).

A técnica diagnóstica de imunocromatografia, ao ser avaliada em comparação com a hemocultura e o TARPME, apresentou uma alta sensibilidade e especificidade em comparação com os demais, sendo, portanto, uma ferramenta útil, rápida e eficaz para auxiliar no diagnóstico da enfermidade (KIM et al., 2007).

A PCR, utilizando como amostras sangue e leite de animais infectados, foi testada em comparação com a hemocultura e o TARP-ME, apresentando-se eficaz no auxílio do diagnóstico da $B$. canis. (OLIVEIRA et al., 2011).

Os exames sorológicos, embora sejam os mais utilizados no diagnóstico da brucelose canina, apresentam dificuldades referentes à disponibilidade de antígenos (Minharro et al., 2005) e estão sujeitos a erros de interpretações ocasionados pela possibilidade de reações cruzadas com infecções por outros organismos, tais como 
Pseudomonas, Bordetella bronchseptica e Actinobacillus equuli (ETTINGER; FELDMAN, 1997).

\subsection{Tratamento}

Pode-se empregar antibioticoterapia associada à castração a fim de se eliminar secreções genitais e a transmissão venérea. Porém, esses cuidados não evitam por completo a possibilidade de que o animal possa permanecer como fonte de infecção para outros animais ou seres humanos (NELSON; COUTO, 2010). Estas medidas estão sendo empregadas em casos específicos de animais de alto valor afetivo e/ou econômico, preferencialmente, na ausência de crianças no domicílio (MEGID et al., 2002).

O tratamento não é indicado para animais reprodutores de canis, bem como para animais que não podem ser isolados e monitorados após a antibioticoterapia, já que a recidiva após o tratamento é comum. Mesmo o agente sendo eliminado, os machos normalmente permanecem estéreis devido aos danos irreparáveis nos testículos e epidídimo (SCHIN; CARMICHAEL, 1999).

A antibioticoterapia com melhor eficácia é resultante da associação de tetraciclinas (ex.: cloridrato de tetraciclina, doxiciclina, minociclina) a aminoglicosídios (ex.: estreptomicina) (SCHIN; CARMICHAEL， 1999). Como proposta de protocolo terapêutico pode-se citar doxiciclina, $10 \mathrm{mg} / \mathrm{kg}$, VO, SID/BID, por 28 dias, associada a diidroestreptomicina, $10 \mathrm{mg} / \mathrm{kg}$, IM, TID, na primeira e quarta semanas da terapia (CRIVELLENTIN, L.Z.; BORINCRIVELLENTIN, 2015).

\subsection{Profilaxia e controle}

As medidas de prevenção da brucelose por $B$. canis baseiam-se em aspectos sanitários, controle sorológico regular dos animais do canil, eliminação dos positivos, castração de cães infectados, isolamento das fêmeas em parição, desinfecção sistemática do canil e quarentena antes da introdução de novos animais

(FLORES-CASTRO;

CARMICHAEL， 1981; BERTHELOT; BASTUJI, 1996).

Deve ser realizado o isolamento dos animais suspeitos, tais como as fêmeas que apresentaram abortos ou infertilidade após vários cruzamentos sucessivos e os machos com sinais de problemas genitais. $\mathrm{O}$ isolamento deve ser mantido até que os exames laboratoriais tenham sido concluídos, devendo os animais positivos ser eliminados e os negativos, antes de serem liberados, deverão ser retestados, sendo necessárias, pelo menos, três provas com resultados negativos, com intervalo de 30 dias, para que o animal seja considerado negativo

(FLORES-CASTRO;

CARMICHAEL, 1981). 
Animais infectados devem ser eliminados de programas de cobertura e submetidos à antibioticoterapia, reduzindo, dessa forma, a possibilidade de transmissão ao ser humano (MEGID et al., 2000).

Existem estudos com vacinas que utilizam DNA recombinante mostrando que estas podem ser promissoras para prevenção da doença. A ação dos anticorpos vacinais pode ser explicada pela morte da $B$. canis através da ativação do complemento, opsonização e fagocitose ou promoção de toxicidade celular dependente das células NK durante a vida extracelular deste patógeno no soro ou membranas mucosas (CLAUSSE et al., 2013).

O controle da brucelose canina é dificultado, muitas vezes, pelo desconhecimento da doença por parte dos tutores de cães, que não procuram orientação veterinária. Isso contribui para permanência da circulação da bactéria, sendo muitos casos de brucelose canina não notificados. Os profissionais veterinários também desempenham papel importante na profilaxia e controle desta enfermidade, visto que têm como dever, orientar os tutores acerca dos cuidados para prevenir a brucelose, além de incluí-la como diagnóstico diferencial em animais com distúrbios reprodutivos, garantindo, assim, medidas de controle eficientes para a doença (MINHARRO et al., 2005).

\subsection{Considerações de saúde pública}

Das espécies conhecidas de Brucella, quatro já foram implicadas em causar doença nos seres humanos: $B$. abortus, B.suis, B. melitensis e B. canis. Por mais que as espécies de Brucella spp. variem quanto à virulência, a proximidade dos seres humanos com animais infectados, mais especificamente, a sua exposição a tecidos ou secreções contaminadas pela bactéria, contribui para infecção humana. A brucelose no homem é considerada uma antropozoonose de caráter ocupacional, estando, muitas vezes, relacionada a acidentes de laboratório, manejo de animais infectados por tratadores, criadores ou veterinários, inoculação acidental ou absorção ocular das vacinas vivas atenuadas contra $B$. abortus ou B.melitensis (GREENE; CARMICHAEL, 2015). Para a B. canis, o risco zoonótico é relativamente alto para pessoas que lidam com reprodução em canis e são expostas a fluidos e tecidos reprodutivos de cães infectados (HOLLETT, 2006). Lucero et al. (2010) isolaram B.canis em uma família de seis pessoas (três crianças e três adultos) que vivia em contato próximo com uma cadela, que tinha histórico de abortamento e teve cultura microbiológica positiva para a bactéria.

Existem diferenças quanto à virulência entre as espécies brucélicas 
capazes de causar doença no ser humano. A maior virulência é observada em infecções por B.melitensis e biovares de B.suis, enquanto B.abortus exibe virulência moderada. Nestas infecções, a espondilite, poliartrite, conjuntivite e uveíte estão entre as manifestações mais comuns. A endocardite brucélica é uma séria e rara complicação, ocorrendo em 1 a $11 \%$ das infecções por Brucella spp. A apresentação clínica da brucelose humana causada por B.canis é semelhante às infecções causadas por Brucella spp. lisas, com sinais e sintomas inespecíficos (MARZETTI et al., 2013). Febre recorrente, cefaleia e fraqueza são mais comumente relatadas, embora, a doença também tenha sido associada a lesões oculares (OPPERMAN et al., 1969) e endocardite (YING et al., 1999). Em todo o mundo, 52 casos de brucelose humana, causada por B.canis, já foram relatados, e, embora, a maioria desses casos envolvam a apresentação de sintomas leves da doença, a infecção, ocasionalmente, pode resultar em doença severa, incluindo aneurismas infecciosos, associada à endocardite brucélica, aborto e osteomielite (KRUEGER, et al., 2014; DENTINGER, et al., 2015). A brucelose apresenta ainda grande impacto para indivíduos imunossuprimidos (pacientes com câncer, HIV positivos e transplantados), mulheres grávidas e crianças (HOLLETT, 2006).
Os tutores de animais pet devem sempre ser informados do perigo potencial para a saúde em manter animais de estimação infectados por B.canis. Os médicos veterinários devem dispor de cuidados de higiene ao examinarem cães suspeitos, particularmente, fêmeas que abortaram. Os funcionários de laboratório devem usar equipamentos de proteção individual, incluindo óculos, máscara, luvas e roupa protetora, além de manusear o micro-organismo em câmara de segurança biológica (GREENE; CARMICHAEL, 2015).

Tendo em vista o potencial zoonótico da brucelose canina e a proximidade em que convivem cães e seres humanos, é importante a implantação de medidas de controle e prevenção da doença nos animais, evitando a sua disseminação para o ser humano.

\section{Considerações finais}

A brucelose canina é uma enfermidade infecto-contagiosa crônica cosmopolita, que tem como principal característica clínica a manifestação de distúrbios reprodutivos nos animais infectados. Pelos prejuízos econômicos que a brucelose pode causar, principalmente em canis de reprodução, e por se tratar de uma zoonose, cabe ao médico veterinário, a partir da suspeita clínica, utilizar-se dos recursos disponíveis para a realização do seu diagnóstico, esclarecendo, junto ao 
tutor do animal, os potenciais riscos à saúde pública. É importante esclarecer também, que mesmo após antibioticoterapia, cães ainda podem permanecer como portadores, o que enfoca ainda mais sobre a necessidade da utilização de medidas profiláticas para evitar o desenvolvimento da doença.

\section{Referências}

1.ALMEIDA, A.C.; SANTORELLI, A.; BRUZADELLI, R.M.Z.; OLIVEIRA, M.M.N.F.Soroepidemiologia da brucelose canina causada por Brucella canis e Brucella abortus na cidade de Alfenas, MG. Arq. Bras. Med. Vet. Zootec., v.56, n.2, 2004.

2. AZEVEDO, S.S.; VASCONCELLOS, S.A.; ALVES, C.J.; KEID, L.B.; GRASSO, L.M.P.S.; MASCOLLI, R.; PINHEIRO, S.R. Inquérito sorológico e fatore de risco para a brucelose por Brucella canis em cães do município de Santana de Parnaíba, Estado de São Paulo, Pesq. Vet. Bras., v. 23, n. 4, p. 156-160, 2003.

3. BAE, D.H.; LEE, Y.J. Occurrence of canine brucellosis in Korea and polymorphism of Brucella canis isolates by infrequent restriction site-PCR. Korean Journal of Veterinary Research, v. 49, p.105-111, 2009.

4. BARKHA, S.; KUMAR, S.D.; KUMAR, S.D. Immunochemical characterization of antigens of Brucella canis and their use in seroprevalence study of canine brucellosis. Asian Pacific Journal of Tropical Medicine, p. 857-861, 2011.

5. BARR, P.C.; EILTS, B.E.; ROY, A.F. et al. Brucella suis biotype 1 infection in a dog. J. Am. Vet. Med. Assoc., v.186, p.686-687, 1986.

6. BARROUIN-MELO, S.M.; POESTER, F.P.; RIBEIRO, M.B.; ALCÂNTARA, A.C.; AGUIAR, P.H.P.; NASCIMENTO, I.L.; SCHAER, R.E.; NASCIMENTO, R.M.; FREIRE, S.M. Diagnosis of canine brucellosis by ELISA using na antigen obtained from wild
Brucella canis. Research in Veterinary Science, v. 83, n. 3, p. 340-346, 2007.

7. BERTHELOT, X.; BASTUJI, B.G.A Brucelose do cão. A hora Veterinária, n. 92, p. 47-50, 1996.

8. BICKNELL, S.R.; BELL, R.A.; RICHARDS, P.A. Brucella abortus in the bitch. Vet. Rec., v.99, p.85-86, 1976.

9. BOSU, W.T.K.; PRESCOTT, J.F. A serological survey of dogs for Brucella canis in southwestern Ontario. Can Vet J., n.21, p.198-200, 1980.

10. BROWER, A.; OKWUMABUA, O.; MASSENGILL, C.; MUENKS; VANDERLOO, M.D.; HOMB, K.; KURTH, $\mathrm{K}$. Investigation of the spread of Brucella canis via the U.S. interstate dog trade. International Journal of Infectious Diseases, v. 11, n.5, p. 454-458, 2007.

11. CARMICHAEL, L.E. Abortion in 200 beagles. Journal of the American Veterinary Medical Association, v.149, p.1126, 1966.

12. CARMICHAEL, L.E.; KENNEY, R.M. Canine Abortion caused by Brucella canis. Journal of the American Veterinary Medical Association, v.152, n.6, p.605-616, 1968.

13. CARMICHAEL, L.E. Canine brucellosis: na annotates review with selected cautionary comments. Theriogenology, v. 6, n.2-3, p. 105-116, 1976.

14. CARMICHAEL, L.E.; ZOHA, S.J.; FLORES-CASTRO, R. Problems in the serodiagnosis of canine brucellosis: dog responses to cell wall and internal antigens of Brucella canis. Dev. Biol. Stand., v. 56, p.371-83, 1984.

15. CARVALHO, M.R.; MOLNAR, L.; MOLNAR, E.; DIAS, H.L.; LIMA, E.S.C. Ocorrência da Brucella canis e Brucella abortus em cães criados no Estado do Pará. Revista de Ciências Agrárias. 34: 69-76, 2000 
16. CASTRILLON-SALAZAR, L.; GIRALDO-ECHEVERRI, C.A.; SANCHEZJIMENEZ, M.M.; OLIVERA-ANGEL, M. Factores asociados con la seropositividad a Brucella canis en criaderos caninos de dos regiones de Antioquia, Colombia. Cad. Saúde Pública, v.29, n.10, p.1955-1973, 2013.

17. CHINYOKA, S.; DHLIWAYO, S.; MARABINI, L.; DUTLOW, K.; MATOPE, G.; PFUKENYI, D.M. Serological survey of Brucella canis in dogs in urban Harare and selected rural communities in Zimbabwe. Journal of the South African Veterinary Association, v.85, n.1, Art.1087, 5 pages, 2014.

18. CLAUSSE, M.; DÍAZ, A.G.; GHERSI, G.; ZYLBERMAN, V.; CASSATARO, J.; GIAMBARTOLOMEI, G.H.; GOLDBAUM, F.A.; ESTEIN, S.M. The vaccine candidate BLSOmp31 protects mice against Brucella canis infection. Vaccine, v. 31, n. 51, p. 61296135, 2013.

19. CORRÊA, W.M; CORRÊA, C.N.M. Enfermidades Infecciosas dos Mamíferos Domésticos. 2th ed. Rio de Janeiro: Medsi, 1992.195-215p.

20. CORRENTE, M.D.; FRANCHINI, N.; DECARO, G.; GRECO, M.D.; ABRAMO, M.F.; GRECO, F.; LATRONICO, F.; CROVACE, A.; MARTELLA, V. Detection of Brucella canis in a dog in Italy. New Microbiology, v.33, p.337-341, 2010.

21. CORTES, V.A.; OLIVEIRA, M.C.G.; ITO, F.H.; VASCONCELLOS, S.A. Reações sorológicas para Brucella canis em cães errantes capturados na proximidade dos parques públicos, reservas florestais e em áreas periféricas do Município de São Paulo, Brasil. Rev. Fac. Med. Vet. Zootec. Univ. S. Paulo, v.25, p.101-107, 1988.

22. CRIVELLENTIN, L.Z.; BORINCRIVELLENTIN, S. Casos de rotina em medicina veterinária de pequenos animais. 2th ed. São Paulo : MedVet., 2015.151-152p.

23. DENTINGER, C.M.; JACOB, K.; LEE, L.V. et al. Human Brucella canis infction and subsequent laboratory exposures associates with a puppy, New York city, 2012. Zoonoses

Public Health, v.62, n. 5, p. 407-14, 2015.

24. DORNELES, E.M.S.; SANTOS, H.; MINHARRO, S.; NASCIMENTO-ROCHA, J.M.; MATHIAS, L.A.; DASSO, M.G.; TIENSOLI, C.D.; HEINNEMAN, M.B.; LAGE, A.P. Anticorpos anti-Brucella canis e anti-Brucella abortus em cães de Araguaína, Tocantins. Braz. J. Vet. Res. Anim. Sci., v. 48, n. 2, p. 167-171, 2011.

25. DUNNE J.; SEHGAL K.; MCMILLAN A.; PERRET L. Canine brucellosis in a dog imported into the UK. Vet. Rec., v.15, p. 247, 2002.

26. ETTINGER, S.J; FELDMAN, E.C. Tratado de Medicina Interna Veterinária . 4th ed. São Paulo: Manole, 1997. 534-535p.

27. FERNANDES, J.C.T., WALD, V.B., JOBIM, G.B. Isolamento de Brucella canis do humor aquoso de um cão com lesões oculares. Arq. Fac. Vet. v.4, p.109-113, 1976-1977.

28. FERNANDES, A.R.F., AZEVEDO, S.S.; PIATTI, R.M.; PINHEIRO, E.S.; GENOVEZ, M.E.; AZEVEDO, A.S.; BATISTA, C.S.A.; ALVES, C.J. Brucella canis infection in dogs attended in veterinary clinics from Patos, Paraíba state, Brazil. Brazilian Journal of Microbiology, v. 42, p. 1405-1408, 2011.

29. FERNANDES, A.R.F.; FERNANDES, A.G.; ROTONDANO, T.E.F.; ALVES, C.J.; KIM, P.C.P.; MOTA, R.A.; AZEVEDO, S.S. Inquérito sorológico e molecular da brucelose canina no município de Natal, Estado do Rio Grande do Norte. Ciência Rural, Santa Maria, v.43, n.9, p.1629-1635, 2013.

30. FERREIRA, T.; MANDELBAUM, M.A.; MARQUES, A.P.L.; TORRES, H.M.; FIGUEIREDO, M.J.; SERRA, C.M.B.; AQUINO, M.H.C. Inquérito sorológico da brucelose canina através da utilização de antígeno externo e interno de Brucella canis e Brucella ovis. R. Bras. Cien. Vet., v. 14, n. 3, p. 167-168, 2007. 
31. FLORES-CASTRO, R.; SEGURA, R.A serological and bacteriological survey of canine brucellosis in Mexico. Cornell Veterinary, v.66, n. 1, p.347-352, 1976.

32. FLORES-CASTRO, R.; CARMICHAEL, L.E. Brucelosis causada por Brucella canis. Ciencia Veterinaria, v.3, p. 178-193, 1981

33. FORBES, L.B.; PANTEKOEK, J.F. Brucella canis isolates from Canadian dogs. The Canadian Veterinary Journal, v.29, p.149-152, 1988.

34. FORBES, L.B. Brucella abortus infection in 14 farm dogs. J. Am. Vet. Med. Assoc., v.196, p.911-916, 1990.

35. GERMANO, P.M.L, VASCONCELLOS, S.A. ISHIZUKA, M.M., PASSOS, E.C.; ERBOLATO, E.B. Prevalência de infecção por Brucella canis em cães da cidade de Campinas, SP, Brasil. Rev. Fac. Med. Vet. Zootec. Univ. São. Paulo., v.24, p.27-34, 1987.

36. GODOY, A.M.; PERES, J.N.; BARG, L. Isolamento de Brucella canis em Minas Gerais. Arq. Esc. Vet. UFMG, v.29, n.1, p.3542, 1977.

37. GOMES, M.J.P.; DRIEMEIER, D.; SOARES, H.C.; BASTOS, C.D.; CANTO, S.P.; BRUM, M.; ROSSI, A.C.; COBERLLINI, L.G. Brucella canis: isolamento em um cão com epididimite e orquite - relato de um caso. Clin. Vet., v.18, p. 17-20, 1999.

38. GOMO, C.Characterization of Brucella species in Zimbabwe. South Africa, 2013. 80p. (MVSc dissertation) - Department of Veterinary Tropical Diseases, University of Pretoria, South Africa, 2013.

39. GOUS, T.A.; VAN RENSBURG, W.J.; GRAY, M., PERRETT, L.L.; BREW, S.D.; YOUNG, E.J.; WHATMORE, A.M.; GERS, S.; PICARD, J. Brucella canis in South Africa, Veterinary Record, v. 157, p.668, 2005.

40. GREENE, C.E.; CARMICHAEL, L.E. Brucelose canina. In: GREENE, C.E. Doenças infecciosas em cães e gatos. 4.ed. Rio de Janeiro: Guanabara Koogan, 2015. p. 23-26.
41. HINIC, V.; BRODARD, I.; PETRIDOU, E.; FILIOUSSIS, G.;CONTOS, V.; FREY, J. Brucellosis in a dog caused by Brucella melitensis Rev 1', Veterinary Microbiology, v. 141, p. 391-392, 2010.

42. HOLLETT, R.B. Canine brucellosis: outbreaks and compliance. Theriogenology, v.66, n. 3, p. 575-587, 2006.

43. LARSSON, M.H.M.A.; COSTA, E.O. Isolation of Brucella canis. Int. J. Zoo., v.7, p. 125-130, 1980.

44. LARSSON, M.H.M.A.; LARSSON, C.E.; MIRANDOLA, R.M.S.; YASSUDA, P.H.; GRUTOLLA, G. Canine Brucellosis in São Paulo: serologic survey of kennel and stray dogs. Int. J. Zoonoses, v.8, p.85-90, 1981.

45. LOPES, C.F.A.; MOLNAR, L.; MOLNAR, E. Avaliação soroepidemiológica da brucelose em animais e humanos procedentes da zona bragantina no estado do Pará - Brasil. Rev Bras Reprod Anim, v.23, n.3, p.429-431, 1999.

46. LOPEZ, G.; AYALA, S.M.; EFRON, A.M.; GOMEZ, C.F.; LUCERO, N.E. A serological and bacteriological survey of dogs to detect Brucella infection in Lomas de Zamora, Buenos Aires province. Rev. argent. microbiol., v. 41, n. 2, p. 97-101, 2009.

47. LUCERO, N.E.; CORAZZA, R.; ALMUZARA, M.N.; REYNES, E.; ESCOBAR, G.I.; BOERI, E.; AYALA, S.M. Human Brucella canis outbreak inked to infection in dogs. Epidemiol. Infect., v.138, p.280-285, 2010.

48. KADEN, R.; AGREN, J.; BAVERUD, V.; HALLGREN, G.; FERRARI, S.; BORJESSON, J.; LINDBERG, M.; BACKMAN, S.; WAHAB, T. Brucellosis outbreak in a Swedish kennel in 2013: determination of genetic markers for source tracing. Veterinary Microbiology, v. 174, p. 523-530, 2014.

49. KANG, S.; HER, M.; KIM, J.W.; KIM, J.; KO, K.Y.; HA, Y.;JUNG, S.C. Advanced 
Multiplex PCR Assay for Differentiation of Brucella Species. Applied and Environmental Microbiology, v.77, n. 18, p. 6726-6728, 2011.

50. KEID, L.B.; SOARES, R.M.; MORAIS, Z.M.; RICHTZENHAIN, L.J.; VASCONCELLOS, S.A. Brucella spp. isolation from dogs from commercial breeding kennels in São Paulo state, Brazil. Braz. J. Microbiol. v.35, n.1-2, p. 161-166, 2004.

51. KEID, L.B.; SOARES, R.M.; VIEIRA, N.R.; MEGID, J.; SALGADO, V.R.; VASCONCELLOS, S.A.; COSTA, M.; GREGORI, F.; RICHTZENHAIN, L.J. Diagnosis of Canine Brucellosis: Comparison between Serological and Microbiological Tests and a PCR Based on Primers to 16S-23S rDNA Interspacer. Veterinary Research Communications, v. 31, p. 951-965, 2007.

52. KEID, L.B.; SOARES, R.M.; VASCONCELLOS, S.A.; MEGID, J.; SALGADO, V.R.; RICHTZENHAIN, L.J. Comparison of agar gel immunodiffusion test, rapid slide agglutination test, microbiological culture and PCR for the diagnosis of canine brucellosis. Research in Veterinary Science, v. 86, p. 22-26, 2009.

53. KRUEGER, W.S.; LUCERO, N.E.; BROWER, A.; HEIL, G.L.; GRAY, G.C. Evidence for unapparent Brucella canis infections among adults with occupational exposure to dogs. Zoonoses Public Health, v. 61, n. 7, p. 509-18, 2014.

54. MAKLOSKI, C.L. Canine brucellosis management. Vet. Clin. Small Anim., v.41, p.1209-1219, 2011.

55. MARASSI, C.D.; MORAES, I.A.; LILENBAUM, W. Soroprevalência de brucelose canina no municípiodo Rio de Janeiro pelo método de lmunodifusão em Gel Agarose. R. bras. Ci. Vet., v. 10, n. 1, p. 63-64, 2003.

56. MARZETTI, S.; CARRANZA, C.; RONCALLO, M.; ESCOBAR, G.I.; LUCERO, N.E. Recent trends in human Brucella canis infection. Comparative
Immunology, Microbiology and Infectious Diseases, v.36, n.1, p. 55-61, 2013.

57. MEGID, J.; BRITO, A.F.; MORAES, C.C.G.; FAVA, N.; AGOTTANI, J. Epidemiological assessment of canine brucellosis. Arq. Bras. Med. Vet. Zootec., v.51, p.439-440, 1999

58. MEGID, J.; RIBEIRO, M.G; MORAES, C.C.G; NARDI JÚNIOR, G.; PAES, A.C.; PRESTES, V; LISTONI, F.J.P. BRUCELOSE CANINA - RELATO DE CASO. Arquivo do Instituto Biológico, São Paulo, v.69, n.4, p.103-106, 2002.

59. MEGID, J.; SALGADO, V.R.; KEID, L.B.; SIQUEIRA, A.K.; MEIRELLES, C.E.; MORETTI, D.M. Infecção em cão por Brucella abortus: relato de caso. Arquivo Brasileiro de Medicina Veterinária e Zootecnia, v. 59, n. 6, p. 1583-1585, 2007.

60. MOORE, J.A.; BENNETT, M. A previously undescribed organism associated with canine abortion. Vet. $\operatorname{Re} c$., v.80, p. 604$5,1967$.

61. MORAES, C.C.G.; MEGID, J.; SOUZA, L.C.; CROCCI, A.J. Prevalência da brucelose canina na microrregião da serra de Botucatu, São Paulo, Brasil. Arq. Inst. Biol. v.69, n.2, p.7-10, 2002.

62. MORISSET, R.; SPINK, W.W. Epidemic canine brucellosis due to a new species, Brucella canis. The Lancet, v. 294, p. 10001002, 1969.

63. NELSON, R.W.; COUTO, C.G. Medicina interna de pequenos animais. 4 th ed. São Paulo: Elsevier, 2010. 936-938p.

64. NOCKLER K.; KUTZER P.; REIF S.; ROSENBERGER N.; DRAEGER A.; BAHN P.; GOLLNER C.; ERLBECK, C. Canine brucellosis-a case report. Berl. Munch. Tierarztl. Wochensch $r$, v. 116, p. 368-372, 2003.

65. OLIVEIRA, M.Z.D.; VALE, V.; KEID, L.; FREIRE, S.M.; MEYER, R.; PORTELA, R.W.; BARROUIN-MELO, S.M. Validation of an ELISA method for the serological diagnosis of canine brucellosis due to Brucella 
canis. Research in Veterinary Science, v. 90, n.3, p.425-431, 2011.

66. OPPERMAN, A.; ROYER, J.; JOUBERT, L.; PAGEAUT, G.; CARBILLET, J.P. La brucellose oculaire. Ann. Anat. Pathol., v.16, p. 499-502, 1969.

67. PAZ, G.S.; ROCHA, K. S.; LIMA, M. S.; JORGE, E.M.; PANTOJA, J.C.F.; MORAES, C.C.G.; LANGONI, H. Seroprevalence for brucellosis and leptospirosis in dogs from Belém and Castanhal, State of Pará, Brazil. Acta Amazonica, v.45, n.3, p. 265270, 2015.

68. PLANG, J.F.; HUDDLESON, I.F.; Brucella infection in a dog. J. Am. Vet. Med. Assoc. v.79, p.251-2, 1931.

69. SANDOVAL, L.A.; RIBEIRO, L.O.C.; AMARAL, L.B.S.; FEITOSA, M.H.; BAZAN, J.M. Incidência da brucelose canina na cidade de São Paulo. O Biológico, v.42, n.32, p.126132, 1976.

70. SCHOLZ, H.C.; HOFER, E.; VERGNAUD G. et al. Isolation of Brucella microti from mandibular lymph nodes of red foxes, Vulpes vulpes, in lower Austria. Vector Borne Zoonotic Dis., v.9, p.153-156, 2009.

71. SCHOLZ, H.C.; NOCKLER, K.; GOLNER, C.P.; et al. Brucella inopinata sp. nov. isolated from a breast implant infection. Int J Syst Evol Microbiol., v. 60, p.801-808, 2010.

72. SHANG, D.Q.; LI, L.Y.; CHENG, R.Z. The investigation of Brucella canis in China. Chin. J.Epidemiol., n.10, p. 24-30, 1989.

73. VARGAS, A.C.; LAZZARI, A.; DUTRA, V.; POESTER, F. Brucelose canina: relato de caso. Ciência Rural, v. 26, n. 2, p. 305-308, 1996. 